\title{
Ergosterol as a Quantifiable Biomass Marker for Diaporthe phaseolorum and Cercospora kikuchii
}

\author{
H. Q. Xue, Crop Science Department, North Carolina State University, Raleigh 27695; R. G. Upchurch and \\ P. Kwanyuen, USDA-ARS Soybean and Nitrogen Fixation Unit, Raleigh, NC 27695
}

\begin{abstract}
Xue, H. Q., Upchurch, R. G., and Kwanyuen, P. 2006. Ergosterol as a quantifiable biomass marker for Diaporthe phaseolorum and Cercospora kikuchii. Plant Dis. 90:1395-1398.

The relationship between ergosterol content and biomass was determined for the soybean fungal pathogens Diaporthe phaseolorum (Cooke \& Ellis) Sacc. var. sojae, causal agent of Phomopsis seed decay, and Cercospora kikuchii (Matsumoto \& Tomoy.), causal agent of leaf blight and purple seed stain. Biomass was manipulated by varying incubation period, and ergosterol was quantified by high-pressure liquid chromatography. Fungal dry mass was linearly correlated with ergosterol content $\left(r^{2}=0.90, P<0.05\right.$ for D. phaseolorum, and $r^{2}=0.95, P<0.01$ for $C$. kikuchii). In vitro ergosterol content of fungi was $3.16 \mu \mathrm{g} / \mathrm{mg}$ for $D$. phaseolorum and $2.85 \mu \mathrm{g} / \mathrm{mg}$ for $C$. kikuchii. Ergosterol content of inoculated seed was qualitatively correlated with observed seed colonization by both pathogens. Soybean variety had a significant effect on fungal colonization by $D$. phaseolorum and ergosterol content. Results show that ergosterol content can be used to quantify colonization of soybean seed by both pathogens.
\end{abstract}

Soybean (Glycine max (L.) Merr.), the largest oilseed crop produced and consumed worldwide, accounted for $56 \%$ of world oilseed production in 2003 (1). Several pathogens can variably reduce the yield and quality of this important source of oil and protein in production areas around the world each year. Two fungal seed pathogens, Diaporthe phaseolorum (Cooke \& Ellis) Sacc. var. sojae and Cercospora kikuchii (Matsumoto \& Tomoy.), occur in most soybean production areas of the United States and are major causes of seed damage and poor seed quality $(2,27)$.

C. kikuchii infects the leaves, stems, and pods of soybean at flowering, causing leaf and stem blighting and purple staining of seed (20). Purple seed stain is agronomically more important than leaf blight. Infected seeds are discolored, with pink to dark purple areas occurring as small blotches or covering the entire seed coat. When infected seeds are planted, the fungus can grow from the seed coat into the cotyledon, eventually extending to the radicle and rootlets (27). The economic loss to producers is lower prices because of reductions in seed grade as well as lost productivity from decreased rates of seed

Corresponding author: R. G. Upchurch

E-mail: greg_upchurch@ncsu.edu

Accepted for publication 2 June 2006.

DOI: $10.1094 /$ PD-90-1395

This article is in the public domain and not copyrightable. It may be freely reprinted with customary crediting of the source. The American Phytopathological Society, 2006. germination as heavily infected seeds may be nonviable $(17,20,25)$.

Signs of D. phaseolorum infection usually appear first on the petioles of lower leaves and branches as many black pycnidia, which then subsequently develop on pods at yellow pod stage $(24,26)$. Within the seed, the fungus can colonize all tissues of the seed coat and cotyledons, and eventually the radicle and plumule. Infected seeds are frequently covered with white mycelium, may appear shriveled, produce lower quality oil and meal, and may have reduced germination. Severely infected seed can lead to grade reductions and lower prices $(9,24)$.

Since both pathogens can over season in soybean seed, an important part of disease management is to plant seed of moderately resistant soybean cultivars (15), free or nearly free of pathogen. The level of seed colonization by these fungi is therefore an important aspect of seed quality evaluation. One of the most commonly used methods, other than inspection, to detect and quantify fungal contamination of grains and biotic materials is the dilution plating or CFU method (11). However, while the CFU method can effectively enumerate pathogen species, counts may not always accurately reflect changes in fungal biomass, as CFU results depend more on whether the fungi have sporulated than on actual biomass production $(10,21)$.

Ergosterol is a fungi-specific membrane sterol that is absent from higher plants $(12,28)$ and has been widely used $(19,22,23)$ to quantify fungal biomass in inoculated plant tissues. This sterol is rapidly measured with high sensitivity and specificity by high-pressure liquid chroma- tography (HPLC) (18). Ergosterol has been used as a biomass marker for Aspergillus ruber infection in stored soybeans. A quantitative relationship has been demonstrated between ergosterol accumulation in seed infected by $A$. ruber and decreased oil quality (6).

Because soybean breeders are developing high-quality oil lines with altered fatty acid composition (4), it is important to apply the most quantitative method available to determine whether these lines have altered susceptibility to seed pathogens. Since no information is available on the use of ergosterol as a biomass marker for D. phaseolorum or C. kikuchii, we began this study to determine whether a quantitative relationship exists between ergosterol accumulation and biomass for these two fungi. Further, we sought to determine whether ergosterol accumulation could be used as a reliable measure of seed colonization by these fungi.

\section{MATERIALS AND METHODS}

Fungal cultures and growth condition. D. phaseolorum isolate DPM was obtained from the National Soybean Pathogen Collection Center, University of Illinois, Urbana. C. kikuchii ATCC 86864, a toxigenic strain, was provided by J. B. Sinclair (University of Illinois, Urbana). Cultures were grown and maintained on potato dextrose (PD) agar or broth (Difco Laboratories, Detroit, MI) using hyphal tip transfer. To produce liquid cultures, two 5-mm agar plugs were taken from the periphery of a 4-day-old fungal colony and homogenized by vortexing $(10 \mathrm{~min})$ in a sterile screwtop tube that contained $4 \mathrm{ml}$ of sterile water and 1 inch of sterile 4-mm glass beads. One milliliter of each suspension was inoculated into $50 \mathrm{ml}$ of PD broth in a 125-ml flask. Liquid cultures were grown agitated $(180 \mathrm{rpm})$ at $23^{\circ} \mathrm{C}$ in an incubator-shaker with continuous light $\left(15.2 \mu \mathrm{E} \cdot \mathrm{m}^{-2} \cdot \mathrm{s}^{-1}\right)$. Triplicate samples of each fungus were harvested at 3, 4, 5, 6, 7, and 8 days after inoculation by vacuum aspiration onto sterile Miracloth filters (Calbiochem, LaJolla, CA). Samples were stored at $-20^{\circ} \mathrm{C}$ until all were harvested. Samples were then lyophilized to obtain a dry weight measurement and afterwards ground to a fine powder using liquid nitrogen. Powdered mycelium was stored at $-20^{\circ} \mathrm{C}$ until extraction for ergosterol. This experiment was then repeated. Mycelia suspensions for seed inoculation were prepared from 
freshly harvested fungal cultures. Hyphal masses were fragmented in a blender by pulsing the entire fungal culture twice, each time for $20 \mathrm{~s}$. Fragmented mycelia were harvested by vacuum, rinsed on the filter two times with sterile water, and allowed to air-dry until surface water disappeared. Standardized suspensions were produced by adjusting mycelium weight to approximately $2 \mathrm{~g}$ of each fungus per $100 \mathrm{ml}$ of sterile water, followed by mixing.

Soybean varieties and seed inoculation. Five Glycine max lines were chosen based on the $\mathrm{C}_{18}$ fatty acid composition of their seed at maturity (Table 1). Seeds of the five soybean varieties were provided by J. W. Burton, ARS Soybean \& Nitrogen Fixation Unit, North Carolina State University, Raleigh. A6 (8), a maturity group 0 mutant line, is high $(22 \%)$ in stearic acid content, and N01-3544 (4), a maturity group IV, is a mid-oleic-acid (52\%) line. N99-3170, a maturity group VI line, is high (64\%) in linoleic acid, and N83-375 is relatively high $(9 \%)$ in linolenic acid. Cultivar Dare, a maturity group V with $3 \%$ stearic and $21 \%$ oleic acid, was selected as the standard variety for the purpose of comparison. The leaves of all five soybean varieties appeared to be similarly susceptible to both pathogens as evidenced by leaf lesions of equal size and number at day 10 postinfection. The testa was removed from each seed to eliminate a potential barrier to

Table 1. $\mathrm{C}_{18}$ fatty acid profiles of mature seed of soybean varieties used for pathogen infection studies

\begin{tabular}{lcccc}
\hline Variety & $\begin{array}{c}\text { \% Stearic acid, } \\
\mathbf{1 8 : 0}\end{array}$ & $\begin{array}{c}\text { \% Oleic acid, } \\
\mathbf{1 8 : 1}\end{array}$ & $\begin{array}{c}\text { \% Linoleic acid, } \\
\mathbf{1 8 : 2}\end{array}$ & $\begin{array}{c}\text { \% Linolenic acid, } \\
\mathbf{1 8 : 3}\end{array}$ \\
\hline A6 & 22 & 22 & 43 & 5 \\
N01-3544 & 3 & 52 & 33 & 3 \\
N99-3170 & 4 & 24 & 64 & 5 \\
N83-375 & 4 & 21 & 55 & 9 \\
Dare & 3 & 21 & 58 & 8 \\
\hline
\end{tabular}

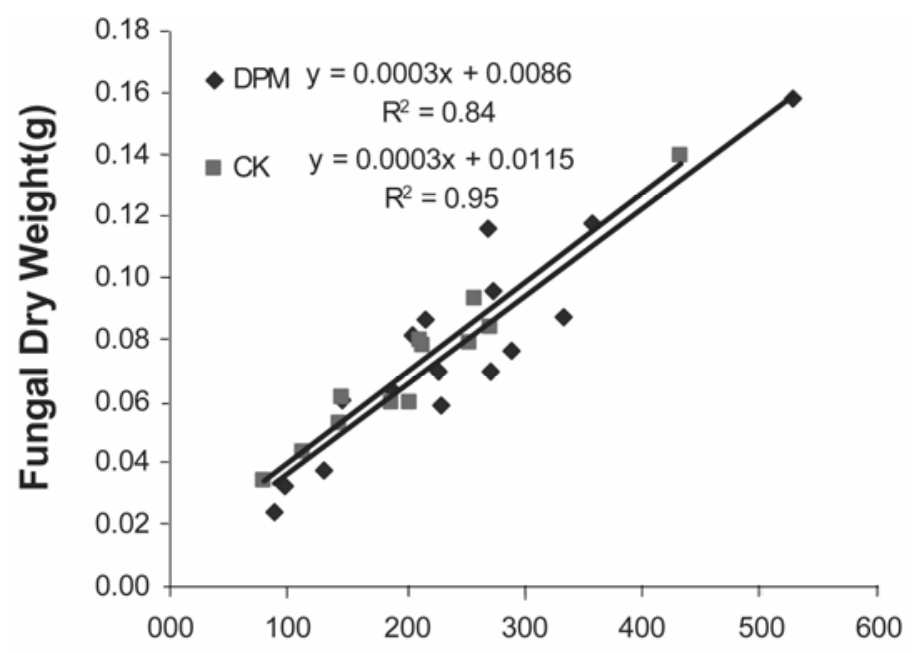

Ergosterol Content $(\mu \mathrm{g})$

Fig. 1. Relationship between fungal dry weight and ergosterol content in Diaporthe phaseolorum or Cercospora kikuchii grown in vitro. tion levels $(0,5,10$, and $20 \mu \mathrm{l})$ with cultivar Dare and three experiment replications. (ii) Ergosterol content was determined for cotyledons of the five soybean varieties (A6, N01-3544, N99-3170, N83-375, and Dare) inoculated with a 5- $\mu$ l suspension of D. phaseolorum or C. kikuchii, with three experiment replications. Both experiments were repeated.

Ergosterol assay. Powdered mycelium or cotyledon samples (approximately 100 $\mathrm{mg}$ ) were extracted overnight at room temperature with $2 \mathrm{ml}$ of chloroformmethanol (1:1). Ergosterol extraction was done in 1-dram brown glass, Teflon screwtop sealed vials on a shaker $(180 \mathrm{rpm})$ as described by Gilbert et al. (7). The top 500 $\mu \mathrm{l}$ of the extract was removed from the vial, avoiding particulates, and passed through a $0.45-\mu \mathrm{m}$ syringe filter. Samples were stored at $4^{\circ} \mathrm{C}$ until analysis by HPLC. Samples $(20 \mu \mathrm{l})$ were injected and analyzed using a Hewlett Packard 1050 automated sampling instrument. An isocratic program was run at room temperature using a mobile phase of $100 \%$ methanol at a flow rate of $1 \mathrm{ml} / \mathrm{min}$. The $4.6 \mathrm{~mm} \times 25$ $\mathrm{cm} \mathrm{C}_{18}$ column with guard was supplied by Alltech Assoc., Inc. (Deerfield, IL). Absorbance was monitored at $282 \mathrm{~nm}$. Ergosterol eluted at about 10 min and was identified by comparison of the retention time with that of an authentic ergosterol standard supplied by Aldrich (Milwaukee, WI). A standard curve obtained by analyzing a series of ergosterol dilutions produced a highly significant linear relationship between ergosterol concentration and the peak area $\left(r^{2}=1, P<0.001\right)$. Calculations were done to express ergosterol in micrograms per milligram of fungal dry weight.

Statistical analyses. Data from randomized complete block design tests were subjected to analysis of variance using the general linear model procedure (PROC GLM) of SAS version 8.2 (SAS Institute, Cary, NC). Means were separated by Fisher's protected t-test. The relationship between ergosterol content and biomass was tested for linearity using the linear regression analysis procedure (PROC REG) of SAS version 8.2.

\section{RESULTS}

Ergosterol content in $D$. phaseolorum and C. kikuchii mycelium. Dry mass and the ergosterol content in the mycelium of D. phaseolorum and C. kikuchii increased significantly $(P<0.01)$ during the 8 -day growth period in PD broth. A linear relationship (Fig. 1) was found between ergosterol content and mycelium dry mass $\left(r^{2}=\right.$ $0.90, P<0.05$ for $D$. phaseolorum: and $r^{2}$ $=0.95, P<0.01$ for $C$. kikuchii). Ratios of ergosterol to dry mass from days 3 through 8 were essentially constant for both $D$. phaseolorum $(3.16 \mu \mathrm{g} / \mathrm{mg})$ and C. kikuchii (2.85 $\mu \mathrm{g} / \mathrm{mg})$, which means that culture age did not significantly affect ergosterolto-dry mass ratios in these two fungi. This 
result indicates that ergosterol can be used as a predictor of fungal biomass for $D$. phaseolorum and C. kikuchii.

Inoculation of cultivar Dare with different levels of the two pathogens. Fungal growth score and ergosterol content per seed weight unit of inoculated Dare soybeans (Fig. 2) were highly correlated for both pathogens $\left(r^{2}=0.77, P<0.001\right.$ for $D$. phaseolorum; $r^{2}=0.86, P<0.001$ for $C$. kikuchii). Ergosterol assays also revealed that noninoculated soybean controls did not contain extractable ergosterol or other plant sterols that could interfere with ergosterol detection (data not shown). The substantial positive correlation between fungal growth score and ergosterol content per seed weight unit suggests that ergosterol content can be used to quantify fungal biomass of either pathogen in infected soybean seed.

Inoculation of soybean varieties differing in fatty acid composition. Ergosterol content per seed weight unit varied significantly $(P<0.0001)$ among the five varieties inoculated with $D$. phaseolorum (Fig. 3), suggesting that differences in fatty acid composition may affect seed colonization by this pathogen. The extent of seed colonization by $D$. phaseolorum in terms of mean ergosterol content $(\mu \mathrm{g} / \mathrm{g}$ of seed dry wt) in order from highest to lowest was: N99-3170 (811), N83-375 (697), Dare (583), N01-3544 (403), and A6 (199). Although lower levels of ergosterol were measured in N99-3170 and Dare, no significant differences in ergosterol content (mean, 130 to $235 \mu \mathrm{g} / \mathrm{g}$ of seed dry wt) were detected in the five soybean varieties inoculated with C. kikuchii (Fig. 3). Overall, in this set of experiments, fungal growth was significantly correlated with ergosterol content for $D$. phaseolorum $\left(r^{2}\right.$ $=0.73, P<0.001)$ and for C. kikuchii $\left(r^{2}=\right.$ $0.34, P<0.05)$.

\section{DISCUSSION}

Ergosterol content and fungal biomass may not always be highly correlated and must be experimentally validated for each fungal species and condition. For example, results from Bermingham et al. (3) showed that only three out of nine aquatic hyphomycete species investigated had a significant correlation between ergosterol content and biomass.

Other research has shown that the ergosterol content per milligram of dry weight in aquatic hyphomycetes varies by a factor of 14 in response to inoculum quality, growth medium richness, and degree of aeration (5). Variation in the ergosterol content between different fungal species and growth stages has also been reported. Olsson et al. (14) found that ergosterol was not a suitable biochemical marker for estimating the biomass of arbuscular mycorrhizal fungi, although earlier work by Salmanowicz and Nylund (18) found little varation in the ergosterol content of pure cultures of mycorrhizal fungi. These results suggest that culture age may confound the correlation between ergosterol content and biomass differently among fungal species. There is general agreement that the ideal sample for fungi grown in vitro should be taken during the exponential growth phase (5) as we have done in this work.

Ergosterol content for fungi grown in vitro is usually expressed in relation to mycelium dry mass (21). In the present study, we found ergosterol content mean values of $3.16 \mu \mathrm{g} / \mathrm{mg}$ for D. phaseolorum and
$2.85 \mu \mathrm{g} / \mathrm{mg}$ for $C$. kikuchii, which remained constant over 5 days of growth Seitz et al. (22) also reported that ergosterol content was relatively constant from 2 days to 3 weeks in cultures of two Aspergillus and Alternaria species. The ergosterol values that we determined for $D$. phaseolorum and $C$. kikuchii are within the wide range (1 to $50 \mu \mathrm{g} / \mathrm{mg}$ of fungal tissue) of published data for other fungal species (13) and specifically within the range for filamentous fungi (2.6 to $14 \mu \mathrm{g} / \mathrm{mg}$ of dry mass) reported by Pasanen et al. (16). A similar range of ergosterol content has also

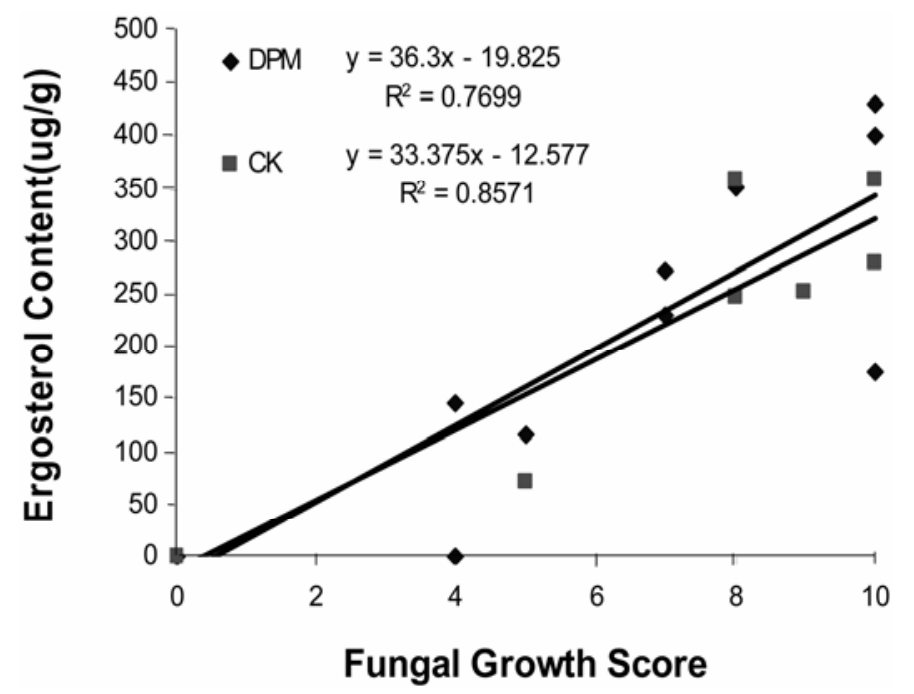

Fig. 2. Relationship between ergosterol content and fungal growth in soybean cultivar Dare seeds inoculated with differing levels of Diaporthe phaseolorum or Cercospora kikuchii.

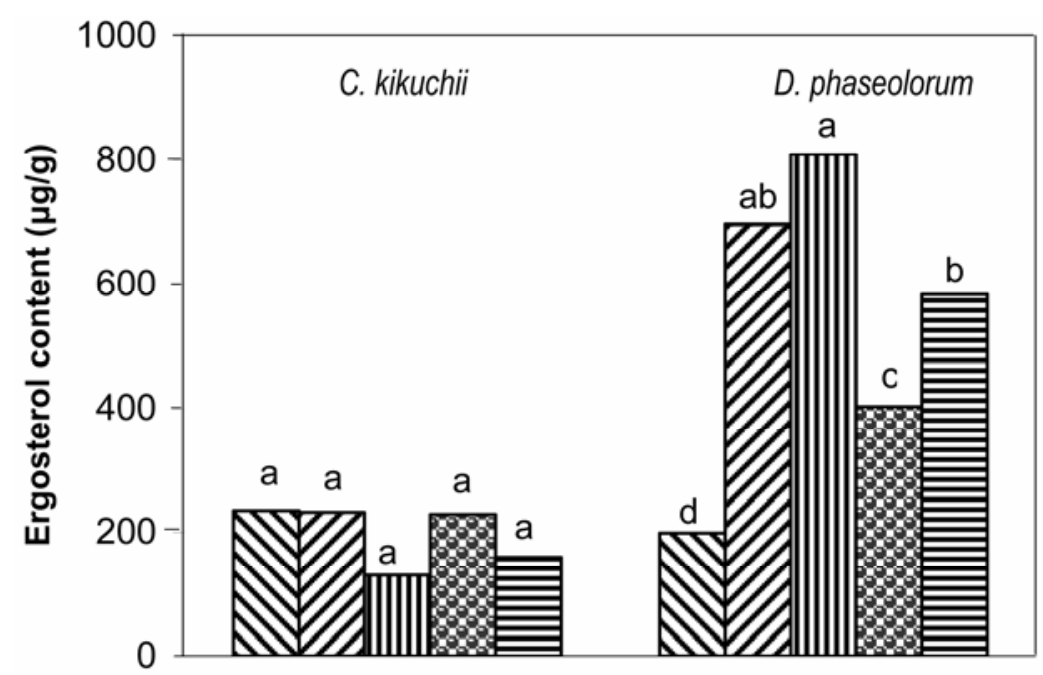

\section{Soybean varieties inoculated with $C$. kikuchii or D. phaseolorum}

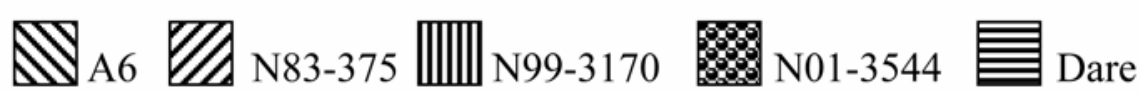

Fig. 3. Extent of fungal colonization (ergosterol content) by Diaporthe phaseolorum or Cercospora kikuchii in soybean varieties differing in fatty acid composition. Means followed by identical letters are not significantly different at $P=0.05$. 
been reported for several other fungal species $(11,21,22)$.

The strong linear relationship between ergosterol content and mycelium dry mass observed for D. phaseolorum and C. kikuchii suggests that ergosterol content can be used to quantify fungal biomass when soybean cotyledons are experimentally inoculated with these fungi. We found a general linear relationship between ergosterol content expressed per dry seed mass unit and a visual assessment of tissue colonization, although we think that the measurement of ergosterol has more power to detect differences in colonization, particularly when seeds are extensively colonized by these fungi.

Our data suggest that fatty acid composition may be one factor that influences the extent of seed colonization by $D$. phaseolorum. Further, a high level of stearic acid, as found in A6 soybeans, may inhibit seed colonization by $D$. phaseolorum. Our data also suggest that colonization by $C$. kikuchii may not be as sensitive to seed fatty acid composition as is colonization by $D$. phaseolorum. Future work with the ergosterol assay will permit us to screen many soybean varieties in order to obtain a more complete assessment of the effect that seed fatty acid composition has on seed colonization by these fungi.

\section{ACKNOWLEDGMENTS}

We thank W. Novitzky (USDA-ARS, N.C. State University, Raleigh) for the analysis of soybean seed fatty acid methyl esters prepared from mature soybean seed samples using acid methanolysis. Mention of trade names or commercial products in this article is solely for the purpose of providing specific information and does not imply recommendation or endorsement by the U.S. Department of Agriculture.

\section{LITERATURE CITED}

1. American Soybean Association. 2004. Soy Stats, A Reference Guide to Important Soybean Facts \& Figures. Published online.

2. Athow, K. L. 1987. Fungal diseases. Pages 687-727 in: Soybeans: Improvement, Production, and Uses, 2nd ed. Agron. Monogr. 16.
Am. Soc. Agron., Madison WI.

3. Bermingham, S., Maltby, L., and Cooke, R. C. 1995. A critical assessment of the validity of ergosterol as an indicator of fungal biomass. Mycol. Res. 99:479-484.

4. Burton, J. W., Wilson, R. F., Novitzky, W., Rebetzke, G. J., and Pantalone, V. R. 2005. Registration of N98-4445A, a mid-oleic soybean germplasm line. Crop Sci. 46:1010-1011.

5. Charcosset, J.-Y., and Chauvet, E. 2001. Effect of culture conditions on ergosterol as an indicator of biomass in aquatic Hyphomycetes. Appl. Environ. Microbiol. 67:2051-2055.

6. Dhingra, O. D., Jham, G., and Napoleão, I. T. 1998. Ergosterol accumulation and oil quality changes in stored soybean invaded by Aspergillus ruber (A. glaucus group). Mycopathologia 143:85-91.

7. Gilbert, J., Abramson, D., McCallum, B., and Clear, R. 2001. Comparison of Canadian Fusarium graminearum isolates for aggressiveness, vegetative compatibility, and production of ergosterol and mycotoxins. Mycopathologia 153:209-215.

8. Hammond, E. G., and Fehr, W. R. 1983. Registration of A6 germplasm line of soybean. Crop Sci. 23:192-193.

9. Kmetz, K. T., Schmitthenner, A. F., and Ellett, C. W. 1978. Soybean seed decay: prevalence of infection and symptom expression caused by Phomopsis sp., Diaporthe phaseolorum var. sojae, and D. phaseolorum var. caulivora. Phytopathology 68:836-840.

10. Lord, J. C. 2001. Response of the Wasp Cephalonomia tarsalis (Hymenoptera:Bethylidae) to Beauveria bassiana (Hyphomycetes: Moniliales) as free conidia or infection in its host, the sawtoothed grain beetle, Oryzaephilus surinamensis (Coleoptera: Silvanidae). Biol. Control 21:300-304.

11. Matchan, S. E., Jordan, B. R., and Wood, D. A. 1985. Estimation of fungal biomass in a solid substrate by three independent methods. Appl. Microbiol. Technol. 21:108-122.

12. Nes, W. R. 1977. The biochemistry of plant sterols. Pages 233-324 in: Advances in Lipid Research, vol. 15. R. Paoletti and D. Ž. Kritchevsky, eds. Academic Press, New York.

13. Newell, S. Y., and Miller, J. D. 1987. Ergosterol content of salt-marsh fungi: effect of growth conditions and mycelial age. Mycologia 79:688-695

14. Olsson, P. A., Larsson, L., Bago, B., Wallander, H., and Van Aarle, I. M. 2003. Ergosterol and fatty acids for biomass estimation of mycorrhizal fungi. New Phytol. 159: 7-10.

15. Orth, C. E., and Schuh, W. 1994. Resistance of
17 soybean cultivars to foliar, latent, and seed infection by Cercospora kikuchii. Plant Dis. 78:661-664.

16. Pasanen, A.-L., Yli-Pietilä, K., Pasanen, P., Kalliokoski, P., and Tarhanen, J. 1999. Ergosterol content in various fungal species and biocontaminated building materials. Appl. Environ. Microbiol. 65:138-142.

17. Pathan, M. A., Sinclair, J. B., and McClary, R. D. 1989. Effects of Cercospora kikuchii on soybean seed germination and quality. Plant Dis. 73:720-723.

18. Salmanowicz, B., and Nylund, J.-E. 1988 High performance liquid chromatography determination of ergosterol as a measure of ectomycorrhizae infection in Scots pine. Eur. J. For. Pathol. 18: 291-298.

19. Saxena, J., Munimbazi, C., and Bullerman, L. B. 2001. Relationship of mould count, ergosterol and ochratoxin A production. Int. J. Food Microbiol. 71: 29-34.

20. Schuh, W. 1999. Cercospora blight, leaf spot, and purple seed stain. Pages 17-18 in: Compendium of Soybean Diseases. 4th ed. APS Press, The American Phytopathological Society, St. Paul, MN.

21. Schnurer, J. 1993. Comparison of methods for estimating the biomass of three foodborne fungi with different growth patterns. Appl. Environ. Microbiol. 59:552-555.

22. Seitz, L. M., Mohr, H. E., Burroughs, R., and Sauer, D. B. 1977. Ergosterol as an indicator of fungal invasion in grains. Cereal Chem. 56:1207-1217.

23. Seitz, L. M., Sauer, D. B., Burroughs, R., Mohr, H. E., and Hubbard, J. D. 1979. Ergosterol as a measure of fungal growth. Phytopathology 69:1202-1203.

24. Sinclair, J. B. 1993. Phomopsis seed decay of soybeans-a prototype for studying seed disease. Plant Dis. 77:329-334.

25. Sinclair, J. B. 1995. Reevaluation of grading standards and discounts for fungus-damaged soybean seeds. J. Am. Oil Chem. Soc. 72:1415-1419.

26. Sinclair, J. B. 1999. Diaporthe-Phomposis complex. Page 31 in: Compendium of Soybean Diseases. 4th ed. APS Press, The American Phytopathological Society, St. Paul, MN

27. Sinclair, J. B., and Hartman, G. L. 1999. Soybean diseases. Pages 3-4 in: Compendium of Soybean Diseases. 4th ed. APS Press, The American Phytopathological Society, St. Paul, MN.

28. Weete, J. D. 1980. Lipid Biochemistry of Fungi and Other Organisms. Plenum, New York. 